\title{
DIAGNÓSTICO DIFERENCIAL DE LESÕES FIBRÓTICAS EM FÍGADOS BOVINOS CONDENADOS POR FASCIOLOSE EM MATADOURO FRIGORÍFICO
}

\author{
(Differential diagnosis of fibrotic lesions in bovine livers condemned by fasciolosis in \\ slaughterhouse) \\ Laila Machado Müller, Louisiane Carvalho Nunes, Isabella Vilhena Freire Martins ${ }^{1}$ \\ ${ }^{1}$ Correspondência: lailammuller@yahoo.com.br
}

RESUMO: A fasciolose bovina apresenta alta prevalência na região sul do Espírito Santo e uma das principais características deste processo é a fibrose hepática. Em matadouros frigoríficos é comum a condenação de fígados que apresentam fibrose por fasciolose, mesmo na ausência do parasito. Objetivou-se com este estudo realizar o diagnóstico diferencial de lesões fibróticas em fígados bovinos condenados por esta enfermidade. Foram avaliados macro e microscopicamente fígados bovinos condenados por fasciolose no Sul do Estado do Espírito Santo e consideradas as variáveis: infiltrado inflamatório, fibrose, metaplasia mucoide e macrófagos espumosos nas regiões periportais. Utilizou-se estatística descritiva e teste de Qui-quadrado seguido do teste $\mathrm{V}$ de Cramer a $5 \%$ de probabilidade. No total, 28 fígados foram analisados e revelaram fibrose periportal e infiltrado inflamatório linfocítico predominantemente discretos. Também se verificou inflamação eosinofílica, predominantemente intensa. Os macrófagos espumosos foram observados em $25 \%$ dos casos e a metaplasia mucoide em $39,28 \%$. Houve associação significativa entre fibrose e infiltrado inflamatório linfocítico e vice-versa, entre fibrose e macrófagos espumosos e vice-versa e entre metaplasia e infiltrado inflamatório eosinofílico. Conclui-se com este estudo que a fibrose e o infiltrado inflamatório são as alterações mais frequentes em fígados condenados por fasciolose. Contudo, a fibrose hepática também está associada à presença de macrófagos espumosos, que pode ser decorrente de outras enfermidades. Assim, a fibrose, isoladamente, não deveria ser utilizada como um critério para condenação por fasciolose. Por outro lado, a metaplasia mucoide é uma alteração frequente em animais com esta doença e poderia ser considerada como um critério de julgamento pela histopatologia.

Palavras-chave: condenação de fígados; Fasciola hepatica, fibrose hepática; macrófagos espumosos

\begin{abstract}
Bovine fasciolosis is highly prevalent in the southern region of the Espírito Santo and the major feature of this process is liver fibrosis. In slaughterhouses condemnation of livers by fasciolosis is common even in the absence of the parasite, taking into consideration only the fibrosis. The aim of this study was to carry out the differential diagnosis of fibrotic lesions in bovine livers condemned by Fasciola hepatica. Bovine livers condemned by fasciolosis in the southern state of Espirito Santo were evaluated macro- and microscopically and the considered variables were: inflammatory infiltrate, fibrosis, mucoid metaplasia and foam cells in the periportal regions. Descriptive statistics and chi-square test followed by Cramer's $V$ test at $5 \%$ probability were performed. In total, 28 livers were analysed and revealed periportal fibrosis and lymphocytic inflammatory infiltrate predominantly discrete. It was also found eosinophilic inflammation, predominantly intense. Foam cells were observed in $25 \%$ of the cases and mucoid metaplasia in $39.28 \%$. There was a significant association between fibrosis and lymphocytic inflammatory infiltrate and vice versa and between metaplasia and eosinophilic inflammatory infiltrate. It can be concluded that fibrosis and inflammatory infiltrate are the most frequent changes in livers condemned by fasciolosis. Nonetheless liver fibrosis is also associated with the presence of foam cells which may be due to other diseases. Thus, fibrosis alone should not be used as a criterion to condemnation by fasciolosis. On the other hand, the mucoid metaplasia is a frequent change in animals with this disease and it could be considered as a criterion of judgment by histopathology.
\end{abstract}

Key Words: Fasciola hepatica; foam cells; liver fibrosis; liver condemnation 


\section{INTRODUÇÃO}

A bovinocultura é uma atividade de grande importância para o Brasil, visto que o país detém o segundo maior rebanho efetivo do mundo e desenvolve dois segmentos muito lucrativos, as cadeias produtivas da carne e leite. $\mathrm{O}$ consumo per capita de carne bovina no Brasil chega a 37,4 kg (MAPA, 2015). Segundo Fruet et al. (2013), o fígado, subproduto da cadeia produtiva de carnes, contribui para o rendimento financeiro de vísceras em matadouros frigoríficos provavelmente por conta do seu elevado peso e, constataram que o fígado foi 0 órgão com maior percentagem de condenação. Vieira et al. (2011) observaram também um grande número de condenações hepáticas em um matadouro frigorífico do Sul do Estado do Espírito Santo, durante os anos de 2008, 2009 e 2010, 102.492 animais que foram abatidos, 44.587 apresentaram lesões hepáticas, totalizando uma condenação de 43,5\%. No Brasil, diversas causas são apontadas para a condenação de fígados em matadouros frigoríficos, sendo as afecções mais frequentes: telangiectasia, hepatite, peri-hepatite, fasciolose, hidatidose e tuberculose (WILSON, 1970; SANTOS, 1986; HERENDA et al., 1994). Ribeiro (2011) inclui outras causas como abscesso, cirrose e esteatose. Há grande dificuldade dos inspetores oficiais em estabelecimentos de abate relacionada à segurança em diagnosticar as diversas enfermidades (FREITAS, 1999). A fasciolose, uma doença parasitária que acomete fígados de bovinos, é de alta prevalência na região sul do Espírito Santo. A lesão macroscópica desse parasitismo inclui a fibrose hepática nas infecções crônicas como principal lesão (ESPINOZA et al., 2010) e, na maioria das vezes, podem ser confundidas macroscopicamente com outras doenças crônicas do fígado, como por exemplo, a intoxicação por Brachiaria spp. A fibrose hepática é um processo comum em várias doenças, tanto no caso de parasitismo por Fasciola hepatica como na intoxicação crônica por plantas hepatotóxicas, como a Brachiaria spp. (LEMOS et al., 1998; BOSTELMANN et al., 2007; GOMAR, 2002; MUSTAFA, 2009). Diante do exposto, objetivou-se com este estudo realizar o diagnóstico diferencial de lesões fibróticas em fígados bovinos condenados por fasciolose em matadouro frigorífico.

\section{MATERIAL E MÉTODOS}

Para a realização deste estudo foram avaliados fígados de bovinos condenados por fasciolose, sem a 
presença do parasito no momento da inspeção do órgão, em dois matadouros frigoríficos do Sul do Estado do Espírito Santo. Foram realizadas quatro visitas aos matadouros frigoríficos dos municípios de Atílio Vivácqua e Muniz Freire, ambos sob a autorização e fiscalização do Instituto de Defesa Agropecuária e Florestal do Espírito Santo (IDAF-ES). No momento da inspeção dos fígados, todos os órgãos foram avaliados macroscopicamente e foi realizado primeiramente um corte longitudinal sobre o ducto biliar principal, para constatar se havia ou não parasitos. Em seguida, foram feitos cortes transversais em toda a extensão do parênquima para a confirmação da ausência de parasitismo, sendo selecionados os fígados que apresentavam lesões fibróticas caracterizadas por depressão do parênquima e/ou espessamento e coloração brancacenta do ducto biliar principal, formando "cordões esbranquiçados" em baixo relevo. De cada fígado foram coletados cinco fragmentos do parênquima para análise microscópica. Os fragmentos hepáticos foram colocados em frascos de vidro de boca larga contendo formol a $10 \%$ e, em seguida, direcionados ao Laboratório de Patologia Animal do Hospital Veterinário do Centro de Ciências Agrárias da
Universidade Federal do Espírito Santo. As amostras fixadas foram submetidas ao processamento histológico de rotina e submetidas à microtomia para a secção de cortes histológicos de cinco micrômetros de espessura e depois corados por Hematoxilina-Eosina (HE) (LUNA, 1968). Para evidenciação das lesões fibróticas, cortes do mesmo material foram corados pela técnica histoquímica de Tricrômico de Masson (LUNA, 1968). A análise microscópica do fígado foi realizada de forma descritiva, considerando-se apenas as lesões periportais, em que foram consideradas a presença ou ausência das seguintes variáveis: infiltrado inflamatório, fibrose, metaplasia mucoide ductal, presença de macrófagos espumosos contendo cristais birrefringentes no interior dos ductos. De cada variável obteve-se a intensidade da lesão por método subjetivo semi-quantitativo baseado em escores, a saber: (+) discreta, (++) moderada e $(+++)$ intensa. Para a classificação do grau de fibrose utilizouse o método citado por Oliveira, Sousa e Andrade (2004) que descreveram a fibrose grau 1 caracterizada por acúmulo de matriz extracelular discreta em volta dos espaços porta; a fibrose grau 2 com acúmulo de matriz extracelular formando septos 
incompletos e a fibrose grau $3 \mathrm{com}$ septação completa do parênquima hepático dividindo-o em lóbulos. Para a avaliação do infiltrado inflamatório foram utilizados critérios de Trivilin (2010), para metaplasia mucoide seguiu-se a metodologia de Paula et al. (2014) e para os macrófagos utilizou-se a descrição de Driemeier et al. (1999). Para a avaliação estatística foi utilizado - método descritivo baseado em percentuais. Para a avaliação entre a presença de fibrose e macrófagos espumosos, fibrose e infiltrado linfocítico, fibrose e metaplasia e entre metaplasia e infiltrado eosinofílico utilizou-se o teste de Qui-quadrado seguido do teste $V$ de Cramer a $5 \%$ de probabilidade.

\section{RESULTADOS}

Foram coletadas amostras de 28 fígados de bovinos contendo lesões macroscópicas de fibrose e ausência do parasito Fasciola hepatica. Estas alterações foram observadas em 100\% (28/28) dos fígados avaliados. Além disto foi possível observar atrofia do parênquima. Microscopicamente, 100\% (28/28) dos fígados apresentaram fibrose periportal com acúmulo de matriz extracelular. Juntamente com a fibrose observou-se proliferação de ductos biliares e de vasos sanguíneos. Com relação à intensidade da fibrose, $53,57 \% \%$ (15/28) apresentaram fibrose discreta (grau 1) (Figura 1); 39,28\% (11/28) apresentaram fibrose moderada (grau 2) e 7,14\% (2/28) apresentaram fibrose intensa (grau 3).

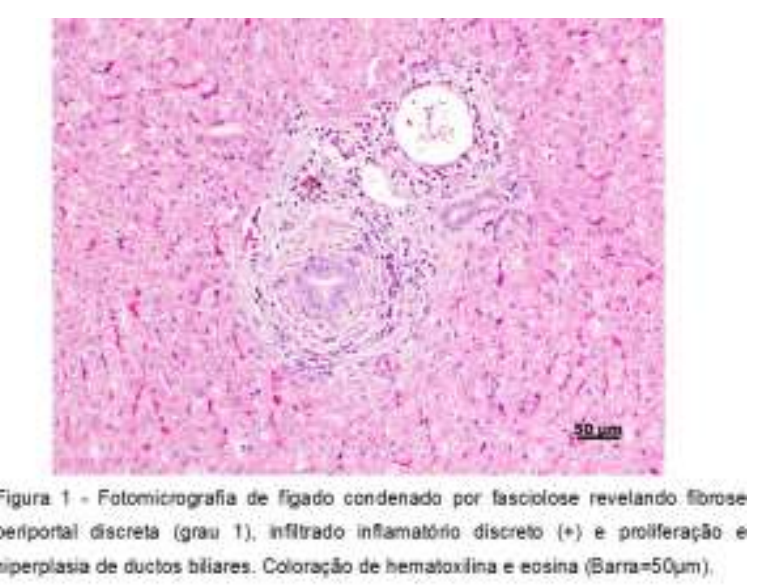

A variável infiltrado inflamatório foi observada em $100 \%$ (28/28) dos fígados sendo o infiltrado predominante o mononuclear composto principalmente por linfócitos. Com relação à intensidade do infiltrado linfocítico verificou-se que $46,43 \%$ (13/28) apresentaram infiltrado inflamatório discreto, $42,86 \%$ (12/28) moderado e $10,71 \%$ (3/28) intenso. Verificou-se que os ductos com infiltrado inflamatório associado também revelaram hiperplasia ductal. Verificouse presença de infiltrado eosinofílico em $25 \%(7 / 28)$. Com relação à intensidade, $28,57 \%(2 / 7)$ apresentaram infiltrado eosinofílico discreto, 28,57\% (2/7) apresentaram infiltrado eosinofílico moderado e $42,86 \%$ (3/7) intenso. Dos 
28 fígados, 25\% (7/28) apresentaram macrófagos espumosos, células gigantes multinucleadas distribuídas pelo parênquima, principalmente na região ao redor das veias centrolobulares e na zona centroacinar. No interior dos macrófagos espumosos notou-se cristais refringentes (Figura 2). Em relação à intensidade observou-se acúmulo de macrófagos espumosos de forma discreta em 71,42\% (5/7), acúmulo de macrófagos espumosos de forma moderada em $14,28 \%$ (1/7) e de forma intensa em $14,28 \%(1 / 7)$.

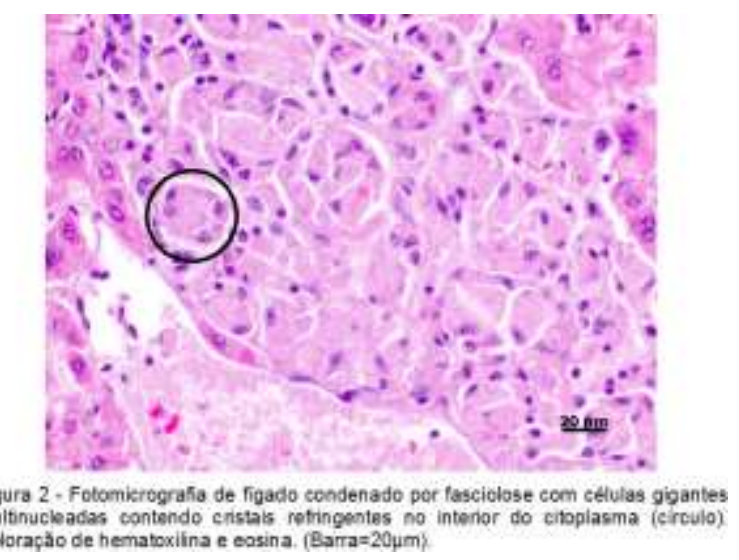

A presença de metaplasia mucoide ou intestinal foi encontrada em $39,28 \%(11 / 28)$ das amostras e revelaram hiperplasia do epitélio ductal, em que as paredes dos ductos mais calibrosos eram intensamente espessadas, com formações irregulares de estruturas glandulares compostas por epitélio colunar alto (Figura 3). Em alguns animais foi possível observar no lúmen do ducto debris celulares indicativos de restos de parasitos adultos. Em relação à intensidade da metaplasia observou-se que esta alteração foi discreta em 27,30\% (3/11) das amostras, moderada em 36,35\% (4/11) e intensa em 36,35\% (4/11).

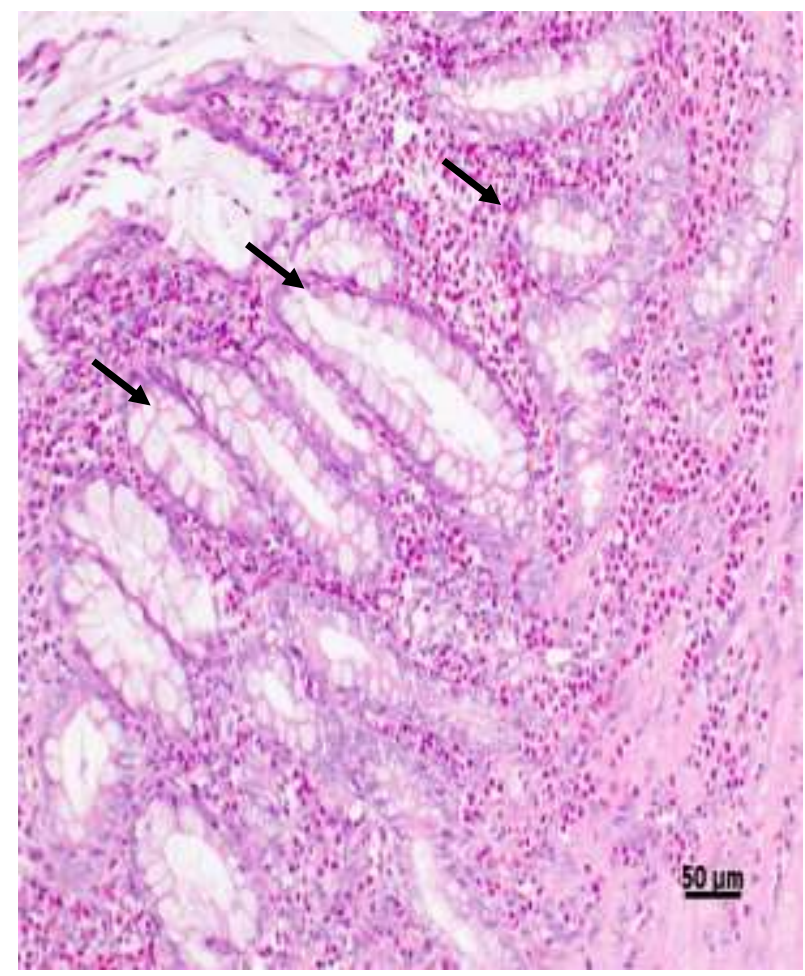

Figura 3 - Fotomicrografia de fígado condenado por fasciolose revelando fibrose grau 3, ducto biliar com metaplasia mucoide intensa (setas) e infiltrado eosinofílico intenso. Coloração de hematoxilina e eosina (Barra=50 $\mathrm{mm}$ ).

Verificou-se que todos os fígados que foram condenados por fasciolose apresentaram fibrose e infiltrado inflamatório e, os que apresentaram maior grau de fibrose revelaram infiltrado inflamatório linfocítico intenso associado. Além disto, encontrou-se macrófagos espumosos nos fígados com maior grau de fibrose, entretanto, sem metaplasia mucoide. Por outro lado, os fígados que revelaram metaplasia mucoide apresentaram infiltrado inflamatório eosinofílico variando de discreta a intensa. Em $14,28 \%$ das amostras foi encontrada metaplasia e macrófagos espumosos concomitantemente. A análise estatística pelo qui-quadrado revelou associação significativa entre a presença de fibrose e infiltrado 
inflamatório linfocítico e vice-versa $(\mathrm{p}=0,0002 ; \quad \mathrm{V}$-Cramer $=0,47)$. Estes dados indicam que a fibrose estava associada ao infiltrado inflamatório linfocítico. Houve associação significativa também entre a fibrose e a presença de macrófagos espumosos e vice-versa $(p=0,019 ; \quad V$-Cramer $=0,27)$, ou seja, quando se verificava fibrose, havia também presença de macrófagos espumosos. No entanto, não houve associação significativa entre a presença de macrófagos e infiltrado linfocítico $(p=0,2341)$. Em relação à variável metaplasia verificou-se que não houve associação significativa com infiltrado inflamatório linfocítico $(p=0,051)$ e entre metaplasia e fibrose $(p=0,1525)$. No entanto, houve associação significativa entre a metaplasia e infiltrado inflamatório eosinofílico ( $p=0,0004$; V-Cramer $=0,36)$.

\section{DISCUSSÃO}

A alteração macroscópica mais marcante deste estudo foi a fibrose, também verificada por Paula et al. (2014), que observou que todos os fígados condenados por fasciolose apresentaram fibrose caracterizada por depressão do parênquima e/ou espessamento da parede dos ductos biliares maiores. No entanto, este tipo de alteração pode ser observado tanto em animais com intoxicação por plantas hepatotóxicas quanto em animais acometidos pela fasciolose (LEMOS et al., 1998; BOSTELMANN et al., 2007; GOMAR, 2002; MUSTAFA, 2009). Apesar de Paula et al. (2014) terem encontrado fibrose em todos os fígados analisados, cerca de $20 \%$ das vísceras não apresentaram parasito no momento da coleta não sendo esclarecida a causa de fibrose nesses fígados. Estes achados servem para confirmar que esta alteração macroscópica do órgão, sozinha, não deveria ser utilizada como diagnóstico definitivo de fasciolose em matadouros frigoríficos uma vez que diversas doenças causam fibrose hepática. Microscopicamente, a fibrose também foi uma alteração marcante neste estudo. Entretanto, verificou-se maior prevalência de fibrose grau 1 , ou seja, fibrose discreta. Achados semelhantes foram encontrados por Paula et al. (2014) que, por meio da análise histopatológica de lâminas coradas pelo método hematoxilinaeosina, verificaram fibrose em todas as amostras. Estes mesmos autores encontraram $72,34 \%$ de prevalência de fibrose grau 1, do tipo discreta, no lobo hepático direito e 55,32\% no lobo esquerdo. Marcos et al. (2007) analisaram 24 amostras de fígados bovinos frescos e concluíram que todos os fígados infectados por $F$. hepatica apresentavam pelo menos um grau de fibrose hepática com predominância de lesões fibróticas graves (66\%) e as associaram ao parasitismo. Estes mesmos autores verificaram que casos de cirrose hepática foram associados à maior densidade parasitária. Trivilin et al. (2013) também sugeriram que há relação entre a presença de parasitos nos ductos biliares e lesões fibróticas mais severas. No entanto, no presente estudo, a prevalência de fibrose grau 3 foi baixa. Desta forma, entende-se que, apesar de todos os fígados utilizados neste estudo terem sido condenados por fasciolose, um dos critérios para a coleta das amostras foi a ausência do parasito adulto. Assim, a ausência do parasitismo poderia justificar o menor grau de fibrose observado. Todavia, Paula et al. (2014) utilizaram apenas fígados contendo parasitos adultos e mesmo assim, observaram fibrose discreta. A partir destes achados é possível inferir que o grau de fibrose não necessariamente está relacionado com maior parasitismo, podendo existir outros fatores como, por exemplo, a reinfecção. $O$ infiltrado inflamatório também foi um achado significativo neste estudo, em que todos dos fígados 
apresentaram essa alteração variando em intensidade discreta a intensa. Bostelmann et al. (2000) citaram que fígados parasitados por $F$. hepatica frequentemente apresentam esta alteração microscópica. Estudo semelhante de Trivilin (2010), que caracterizava histologicamente fígados de bovinos com fasciolose crônica, a maioria das amostras também apresentou infiltrado inflamatório. Por outro lado, Gomar (2002) também encontrou infiltrado inflamatório periductal em $100 \%$ dos fígados de ovinos que consumiam Brachiaria spp. Lemos et al. (1996) e Mustafa (2009) também verificaram em seus trabalhos a presença de infiltrado inflamatório periportal associado ao consumo de Brachiaria spp. Estudos nesta mesma linha foram realizados por Moreira et al. (2009) que encontraram células inflamatórias mononucleares preferencialmente no espaço porta, com pequenos e raros infiltrados no parênquima em animais que consumiram capim braquiária e andropogon. Enquanto que Ringler (2000) verificaram resposta inflamatória do tipo granulomatosa como predominante e observaram macrófagos organizados ou agregados em coleções ou folhetos bastante compactados. Estes dados demonstram que, embora a presença de infiltrado inflamatório seja uma característica frequente em fígados que apresentam lesões em ductos biliares, não pode ser, isoladamente, associada ao diagnóstico determinante de nenhuma doença específica e podem estar associados a outros fatores como o consumo de plantas hepatotóxicas. Em relação ao infiltrado eosinofílico intenso encontrado no presente estudo, Bostelmann et al. (2000) também encontraram essa alteração em fígados infectados por $F$. hepatica de ovinos e bovinos, no entanto, estes tipos celulares foram observados em menor prevalência, assim como neutrófilos.
Estes autores associaram a presença de infiltrado inflamatório eosinofílico à infecção pelo parasito e verificaram maior eosinofilia em ovinos que em bovinos. Neste estudo, verificou-se que quanto maior o grau de fibrose, maior foi a intensidade do infiltrado inflamatório. Da mesma forma, quanto maior o infiltrado inflamatório, maior o grau de fibrose observado. McGavin e Zachary afirmam que a formação da fibrose está relacionada a um processo cicatricial que ocorre a partir de um evento lesivo às células e tecidos, que se inicia por meio de um complexo de respostas defensivas que existem para manter a homeostasia do organismo. Neste estudo foi encontrada uma elevada prevalência de macrófagos espumosos nos fígados avaliados e sabe-se que esta é uma característica importante em animais intoxicados por plantas hepatotóxicas, inclusive Brachiaria spp. Desta forma, acredita-se que estes casos sejam de intoxicação pela planta. No estudo de Moreira et al. (2009) em que analisaram fígados de bovinos que foram alimentados com capim braquiária e capim Andropogon, observaram que a ocorrência de macrófagos espumosos foi maior em animais alimentados com braquiária. Estudos de Driemeier et al. (1998) e Fioravanti (1999) afirmaram a ocorrência de macrófagos espumosos nas zonas periportais em bovinos alimentados com capim do gênero Brachiaria spp., principalmente. No entanto, sabe-se também que a intoxicação por outras plantas como as dos gêneros Panicum e Tribulus também causam a presença dos macrófagos espumosos. Entretanto, os animais abatidos nos frigoríficos avaliados neste estudo são provenientes de regiões onde o pastejo é quase que exclusivo de Brachiaria spp. e a ocorrência de outras plantas que causem lesões semelhantes não tem sido relatadas. Neste estudo verificou-se que quanto maior o grau de 
fibrose, maior a quantidade de macrófagos espumosos encontrados. $\mathrm{Da}$ mesma forma, a presença de macrófagos espumosos ocasionou maior grau de fibrose hepática. Uma vez que não houve relação entre a presença de macrófagos espumosos e infiltrado inflamatório linfocítico, pode-se sugerir que a presença de macrófagos espumosos favoreça a deposição de tecido conjuntivo. A metaplasia mucoide encontrada nos fígados neste estudo foi descrita apenas por Paula et al. (2014). No entanto, acredita-se que seja uma lesão patognomônica da infecção por $F$. hepatica. Estes autores identificaram focos de metaplasia nos fígados com fasciolose crônica sempre associados à presença do parasito adulto e citaram que existe diferença na intensidade de muco produzido frente ao parasitismo. É importante destacar que os focos de metaplasia mucoide neste estudo foram associados tanto ao infiltrado linfocítico quanto eosinofílico. No entanto, houve maior associação ao eosinofílico (36\%), o que reforça que estas lesões possam realmente estar associadas ao parasitismo. Porém não se verificou associação significativa entre a metaplasia mucoide e a fibrose, assim, sugere-se que essa alteração esteja intimamente relacionada aos processos inflamatórios primários. Neste estudo, a fibrose foi associada ou à presença de macrófagos espumosos ou à metaplasia mucoide. Também se verificou que a ocorrência concomitante das lesões de metaplasia e presença de macrófagos espumosos foi baixa, o que se sugere que poucos fígados apresentaram ao mesmo tempo fasciolose e intoxicação por planta hepatotóxica. No entanto, também se verificou uma grande quantidade de fígados com fibrose sem causa esclarecida. Sendo assim, podese afirmar que outras causas ainda não elucidadas também causam fibrose hepática e que estes achados são de extrema importância para que se continue estudando causas de fibrose em fígados de bovinos condenados em matadouros frigoríficos. Em outros estudos de avaliação histopatológica de fígados com fasciolose como os de Bostelmman et al. (2000) e Trivilin (2010) utilizou-se a nomenclatura "formações acinares" para descrever estas modificações do epitélio ductal. Todavia é possível observar que o epitélio ductal, composto por epitélio cúbico simples, sofre modificações transformando-se em epitélio cilíndrico com células e glândulas produtoras de muco e, assim, o termo "metaplasia mucoide" seria melhor empregado. Segundo Brasileiro Filho (2006) a metaplasia é a mudança de um tipo de tecido adulto (epitelial ou mesenquimal) em outro da mesma linhagem e também é um processo adaptativo decorrente da resposta à agressão. Este processo é resultado de irritações persistentes que acabam levando ao surgimento de um tecido mais resistente, como por exemplo, o que ocorre em casos de inflamações crônicas. É importante ressaltar que, independentemente do termo utilizado, é consenso que estas modificações epiteliais ocorrem nos ductos biliares infectados pelo parasito $F$. hepatica. Portanto, é possível a elaboração de um método de diagnóstico diferencial para esta doença baseado nestes achados histopatológicos. No entanto, o diagnóstico em matadouros frigoríficos permanece subjetivo, pois o diagnóstico microscópico é exclusivo do médico veterinário patologista e não há como aplicá-lo na rotina dos estabelecimentos. Considerando estes dados, percebe-se que os métodos utilizados em matadouros frigoríficos para a condenação de órgãos são questionáveis (MENDES; PILATI, 2007). Desta forma, para o diagnóstico de fasciolose, deveria ser utilizada a presença do parasito $F$. hepatica no fígado associada ou não à fibrose como 
critério macroscópico para condenação deste órgão em matadouros frigoríficos. Enquanto que, na ausência do parasito, poderia ser utilizado apenas o termo "fibrose hepática", sem referência a nenhuma doença em específico. Isto minimizaria a superestimação de algumas doenças como a fasciolose e a subestimação de outras doenças como a intoxicação crônica por braquiária. Baptista (2008) relatou que é possível que a frequência de $F$. hepatica influencie nos diagnósticos de outros processos patológicos, pois fígados contendo outras alterações concomitantes com fasciolose geralmente são quantificados em relação ao parasitismo e não pela outra alteração, como por exemplo, a telangiectasia. Portanto, é importante o estabelecimento de novos critérios para a condenação de fígados em matadouros frigoríficos que tragam diagnósticos mais precisos. Desta forma, os dados seriam mais fidedignos.

\section{CONCLUSÃO}

A fibrose e o infiltrado inflamatório são as alterações mais frequentes em fígados condenados por fasciolose em matadouros frigoríficos. No entanto, a fibrose hepática também está associada à presença de macrófagos espumosos, que pode ser decorrente de outras enfermidades. Assim, a fibrose, isoladamente, não pode ser utilizada como um critério para condenação por fasciolose. Por outro lado, a metaplasia mucoide está associada ao infiltrado eosinofílico e é uma alteração frequente em animais com fasciolose. Portanto, na histopatologia, poderia ser considerada como um critério de julgamento.

\section{REFERÊNCIAS}

BAPTISTA, A.T. Quantificações das Condenações em Vísceras de Bovinos em 2007 nos Matadouros-
Frigoríficos do Estado do Espírito Santo registrados no serviço de inspeção estadual. Universidade Castelo Branco, Instituto Brasileiro de Pós-Graduação Qualittas, 2008. Disponível em: $<$ www.qualittas.com.br/artigos/artigo.ph p?artigo_id=527> Acesso em: 18 mar. 2015.

BOSTELMANN, S.C.W.; LUZ, E.; SOCCOL, V.T.; CIRIO, S.M. Histopatologia comparativa em fígados de bovinos, bubalinos e ovinos infectados por Fasciolahepatica. Archives of Veterinary Science, v.5, p.95-100, 2000.

BOSTELMANN, M.; WENDUM, D.; SCHIFFER, E.; DUMONT, S.; REY, C.; LIENHART, A.; HOUSSET, C. Prominent contribution of portal mesenchymal cells to liver fibrosis in ischemic and obstructive cholestatic injuries. Laboratory Investigation, v.87, n.3, p.292-303, 2007.

\section{BRASILEIRO FILHO, G. Bogliolo}

Patologia. 7ed. Rio de Janeiro: Guanabara Koogan, 2006, 1472p.

DRIEMEIER, D. et al. Relação entre macrófagos espumosos ("foam cells") no fígado de bovinos e a ingestão de Brachiaria spp no Brasil. Pesquisa Veterinária Brasileira, v.19, n.2, p.7983, 1999.

ESPINOZA, J. R.; TERASHIMA, A.; HERRERA-VELIT, P.; MARCOS, L. Fasciolosis humana animal en el Perú: impacto en la economia de las zonas endemicas. Revista Peruana de Medicina Experimental y Salud Publica, v.27, n.4, p.604-12, 2010.

FIORAVANTI, M. C. S.; TRINDADE, B. R.; BRUM, K. B.; CARNEIRO, R. B.; MENEZES, L. B.; FRANÇA, A. F. S.; ORSINI, G. F.; SILVA, L. A. F. 2003. Estudo histopatológico do fígado, 
linfonodos mesentérico e aorta de bovinos alimentados com Brachiaria brizantha. XI Enconttro Nacional de Patologia Veterinária (Enapave). 2125 jul., Botucatu, SP.

FREITAS, M.R. Caracterização anatomopatológica de bursites cervicais de bovinos abatidos sob Inspeção Federal no estado de Goiás. 1999. 65f. Dissertação (Mestrado em Ciência Animal) - Escola de Veterinária da Universidade Federal de Goiás, Goiânia.

FRUET, A. P. B.; FABRÍCIO, E. D. A.; KIRINUS, J. K.; SCORTEGAGNA, A.; DÖRR, A. C.; NÖRNBERG, J. L. Perdas econômicas oriundas das condenações de vísceras bovinas em matadouros de Santa Maria, Rio Grande do Sul. Revista Brasileira de Ciência Veterinária. v.20, n.2, p.99-103, abr./jun. 2013.

GOMAR, M.S. Características das células espumosas no fígado, linfonodos mesentéricos e intestino de bovinos associados ao consumo de Brachiaria spp. 2002. 63f. Dissertação (Mestrado em Ciências Veterinárias) - Programa de Pósgraduação em Ciências Veterinárias, Universidade Federal do Rio Grande do Sul, Porto Alegre.

HERENDA, D.; CHAMBERS, P. G.; ETTRIQUI, A.; SENEVIRATNA, P.; DA SILVA, T. J. P. Manual on meat inspection for developing countries. Roma, Itália: Food and Agriculture Organization of the United Nations, 1994. 357p.

LEMOS, R. A. A.; NAKAZATO, L.; HERRERO JUNIOR, G. O.; SILVEIRA A. C.; PORFIRIO, L. C. 1998. Fotossensibilização e colangiopatia associada a cristais em caprinos mantidos sob pastagens de Brachiaria decumbens no Mato Grosso do Sul. Ciência Rural, v.28, n.3, p.507-510.

LUNA, L.G. Manual of the histologic staining methods of the armed forces institute of pathology. 3 ed. New York : McGraw Hill, 1968. 258p.

MARCOS, L. A.; MACHICADO, A.; ANDRADE, R.; SAMALVIDES, F.; SANCHEZ, J.; TERASHIMA, A. Hepatic fibrosis and Fasciola hepatica infection in cattle. Journal of Helmintology, v.8, n.4, p.381-386, 2007.

McGAVIN, M. D.; ZACHARY, J. F. Pathologic Basis of Veterinary Disease. Elsevier. Brasil, 1344p., 2012.

MINISTÉRIO DA AGRICULTURA, PECUÁRIA E ABASTECIMENTO, MAPA. 2015. Disponível em: http://www.agricultura.gov.br/animal/esp ecies/bovinos-e-bubalinos. Acesso em: 10 de junho de 2015.

MENDES, R.E.; PILATI, C. Estudo morfológico de fígado de bovinos abatidos em frigoríficos industriais sob inspeção estadual no Oeste e no Planalto de Santa Catarina, Brasil. Ciência Rural, v.37, n.6, p.1728-1734, 2007.

MOREIRA, C. N.; MORAIS, M.; GARCIA, E. C.; NETO, S. C.; DE ARAÚJO, E. G.; FIORAVANTI, M. C. S. Bovinos alimentados com Brachiaria spp. e Andropogon gayanus: alterações histológicas de fígado e linfonodos. Ciência Animal Brasileira, v. 10. n. 1, p. 206-218, jan./mar. 2009.

MUSTAFA, V.S. Caracterização da intoxicação natural por Brachiaria spp. Em ovinos no Brasil Central. 2009. 80f. Dissertação (Mestrado em Saúde Animal) - Programa de PósGraduação em Saúde Animal, Universidade de Brasília, Brasília. 
OLIVEIRA, L.; SOUZA, M. M.; ANDRADE, Z. A. Capillaria hepaticainduced hepatic fibrosis in rats. (Paradoxical effect of repeated infections). Revista da Sociedade Brasileira de Medicina Tropical, v.37, p.123-127, 2004.

PAULA, F. M. A. B.; SOUSA, D. R.; ARCHANJO, A. B.; CARVALHO, J. R. Caracterização histológica de fígados bovinos com fasciolose crônica. Archives of Veterinary Science. v.19, n.4, p.57-64, 2014.

RIBEIRO, D. B. Estudo anatomo e histopatológico de fígados bovinos e bubalinos criados na ilha de Marajó, estado do Pará, condenados pelo serviço de inspeção estadual. Niterói, 2011.

RINGLER, D. J. Inflamação e reparo. In: JONES, T. C.; HUNT, R. D.; KING, N. W. Patologia veterinária. 6 ed. São Paulo: Manole, 2000. p.119-165.

SANTOS, J.A. Patologia especial dos animais domésticos (mamíferos e aves). Rio de Janeiro: Guanabara, 1986. 576p.

TRIVILIN L.O. Avaliação histopatológica e imunoistoquímica de fígados de bovinos cronicamente infectados por Fasciola hepatica. 2010. Alegre, 100f. Dissertação (Mestrado em Ciências Veterinárias) Programa de Pós-graduação em Ciências Veterinárias, Universidade Federal do Espírito Santo.

TRIVILIN, L.O; SOUSA, D.R.; NUNES, L.C; MARTINS, I.V.F. Imunofenotipagem da resposta inflamatória em fígados de bovinos cronicamente e naturalmente infectados por Fasciola hepática. Revista Brasileira de Medicina Veterinária, v.35, n.1, p.41-47, 2013.
VIEIRA, N.P. et al. Condenação de fígados bovinos na região sul do estado do Espírito Santo. Arquivo Brasileiro de Medicina Veterinária e Zootecnia, v.63, n.6, p.1605-1608, 2011.

WILSON, A. Inspeccion pratica de la carne. Zaragoza, Espanha: Acribia, 1970. 203p. 